\title{
Incidence of embolism and paravalvar leak after St Jude Silzone valve implantation: experience from the Cardiff Embolic Risk Factor Study
}

\author{
A lonescu, N Payne, A G Fraser, J Giddings, G L Grunkemeier, E G Butchart
}

Heart 2003;89:1055-1061

See end of article for authors' affiliations

\section{Correspondence to}

Mr Eric G Butchart,

Department of

Cardiothoracic Surgery,

University Hospital of

Wales, Heath Park, Cardiff

CF14 4XN, UK

egbutchart@aol.com

Accepted 10 April 2003
Background: Silver coating of the sewing ring (Silzone) was introduced as a modification of the $\mathrm{St}$
Jude Medical standard valve to provide antibacterial protection, but the valve has recently been withdrawn.

Objective: To study patients with these prostheses to assess possible adverse effects, and to guide their follow up.

Design: Prospective observational study of risk factors for stroke after valve replacement.

Setting: Cardiology and cardiac surgery departments in a tertiary centre.

Patients: There were 51 patients with Silzone and 116 with St Jude Medical standard valves. Patients undergoing aortic valve replacement were well matched for stroke risk factors. Silzone patients with mitral valve replacement were younger (mean (SD) age 61 (10) v 66 (7) years), more likely to be female $(95 \% \vee 65 \%)$, and had more pulmonary arterial hypertension $(100 \% \vee 78 \%)$, but fewer coronary artery bypass grafts $(5 \% \vee 33 \%)$ than patients with standard mitral valve replacements (all $\mathrm{p}<0.05$ ).

Results: Follow up was 100\% in the Silzone group (mean duration 3.0 (0.9) years) and $97.4 \%$ in the standard group (4.7 (1.4) years). Survival, morbidity, and anticoagulant control were documented over 682 follow up years (153 for Silzone and 529 for standard). There were six embolic strokes and one peripheral embolism in the Silzone group, all within three months after operation, and five embolic strokes and one peripheral embolism in the standard group. Freedom from major thromboembolism at three months was $65 \%$ in the Silzone mitral valve replacement group and $100 \%$ in the standard mitral valve replacement group (difference 35\%, 95\% confidence interval $8 \%$ to $62 \%$ ). There was one reoperation for paravalvar leak in the standard group, but none in the Silzone group (NS). Anticoagulant control in the two groups was similar.

Conclusions: Patients with Silzone mitral valves had a high rate of early postoperative embolism but no excess paravalvar leak.
$\mathrm{T}$ he bactericidal properties of elemental silver have been used in medicine for many years. It was suggested that silver coating of prosthetic valve sewing rings might protect against prosthetic endocarditis. Silver coating of the sewing ring of the St Jude Medical valve (Silzone) was approved by the Food and Drug Administration (FDA) in March 1998, to be marketed under the trade name "St Jude Medical Mechanical Heart Valve SJM Masters Series with Silzone Coating". ${ }^{1}$ Approximately 36000 of these prostheses were implanted before they were withdrawn voluntarily by the manufacturer in January 2000 because of a high incidence of explantation following paravalvar leaks.

Thromboembolism and endocarditis remain major complications of prosthetic valves. ${ }^{2}$ The incidence of thromboembolic events in patients with mechanical prosthetic valves varies according to the valve position and to the presence or absence of established risk factors for stroke. Owing to the major impact of these patient related variables, comparison of one type of valve with another is fraught with methodological difficulties. $^{3}$

In a prospective study of thromboembolic events after valve replacement, designed primarily to investigate patient related factors contributing to thromboembolism, we found a high incidence of early postoperative stroke in patients with St Jude Silzone valves in the mitral position. We therefore undertook a detailed analysis to compare thromboembolic complications between St Jude Silzone and St Jude standard valves.

\section{METHODS}

The Cardiff Embolic Risk Factor Study (CERFS) was designed in 1995 to determine whether patients with an increased thromboembolic risk after valve replacement can be identified prospectively using a combination of perioperative tests. The local research ethics committee approved the protocol, and all patients gave informed consent. Patients were recruited between 1 June 1995 and 31 July 1998, and we report follow up until 7 February 2002. The standard St Jude valve was used between 1 June 1995 and 31 December 1997, and the Silzone valve was used between October 1997 and 31 July 1998. The same five surgeons performed all the operations.

Exclusion criteria were: age less than 18 years, previous valve replacement, operation for infective endocarditis, emergency operation, aortic root replacement, and unwillingness to give informed consent for the study.

\section{Data collection}

Clinical baseline data

The patients' demographic data and previous medical history (including cardiovascular and stroke risk factors and current

Abbreviations: AVERT, artificial valve endocarditis reduction trial; CERFS, Cardiff embolic risk factor study; INR, international normalised ratio; NYHA, New York Heart Association; TIA, transient ischaemic attack 
Table 1 Clinical details of the patients

\begin{tabular}{|c|c|c|c|c|c|c|}
\hline & $\begin{array}{l}\text { Standard } \\
\text { AVR }\end{array}$ & $\begin{array}{l}\text { Silzone } \\
\text { AVR }\end{array}$ & $\mathrm{p}$ Value & $\begin{array}{l}\text { Standard } \\
\text { MVR/DVR }\end{array}$ & $\begin{array}{l}\text { Silzone } \\
\text { MVR/DVR }\end{array}$ & $\mathrm{p}$ Value \\
\hline Number of patients & 70 & 32 & & $35 / 11$ & $13 / 6$ & \\
\hline Follow up (years) & 326 & 104 & & 203 & 49 & \\
\hline \multicolumn{7}{|l|}{ Age (years) } \\
\hline Mean (SD) & $64(10)$ & $61(10)$ & 0.137 & $66(7)$ & $61(10)$ & 0.041 \\
\hline Range & 36 to 80 & 41 to 78 & & 47 to 81 & 44 to 76 & \\
\hline \multicolumn{7}{|l|}{ Sex } \\
\hline Male & $43(61)$ & $20(63)$ & 0.918 & $16(35)$ & $1(5)$ & 0.014 \\
\hline Female & 27 (39) & $12(37)$ & 0.918 & $30(65)$ & $18(95)$ & 0.014 \\
\hline Current smoking & $11(16)$ & $6(19)$ & 0.703 & $3(7)$ & $3(16)$ & 0.240 \\
\hline \multicolumn{7}{|l|}{ NYHA class } \\
\hline |-II & $39(56)$ & $12(37)$ & 0.088 & $9(20)$ & 2 (10) & 0.377 \\
\hline III-IV & 31 (44) & $20(63)$ & 0.088 & $37(80)$ & $17(90)$ & 0.377 \\
\hline CABG at operation & $21(30)$ & $8(25)$ & 0.603 & 15 (33) & $1(5)$ & 0.020 \\
\hline Angina pectoris & $36(51)$ & $17(53)$ & 0.874 & $12(26)$ & $1(5)$ & 0.056 \\
\hline$C A D$ at angiography & $30(43)$ & $10(31)$ & 0.265 & $21(46)$ & $3(16)$ & 0.023 \\
\hline Previous thromboembolism & $6(9)$ & $4(13)$ & 0.536 & $11(24)$ & $3(16)$ & 0.469 \\
\hline \multicolumn{7}{|l|}{ Concomitant disease } \\
\hline Systemic hypertension & $18(26)$ & $10(31)$ & 0.561 & $11(24)$ & $2(11)$ & 0.220 \\
\hline Pulmonary hypertension & 37 (53) & $14(44)$ & 0.393 & $36(78)$ & $19(100)$ & 0.027 \\
\hline Diabetes mellitus & $7(10)$ & $2(6)$ & 0.536 & 5 (11) & $1(5)$ & 0.478 \\
\hline Previous myocardial infarct & $5(7)$ & $1(3)$ & 0.424 & $4(9)$ & $0(0)$ & 0.185 \\
\hline Congestive heart failure & $11(16)$ & $2(6)$ & 0.184 & 31 (67) & $6(32)$ & 0.008 \\
\hline Atrial fibrillation/flutter & $8(11)$ & $4(13)$ & 0.876 & $37(80)$ & $16(84)$ & 0.721 \\
\hline Previous valvotomy & $2(3)$ & $0(0)$ & 0.627 & 5 (11) & $7(37)$ & 0.040 \\
\hline \multicolumn{7}{|l|}{ Valve pathology } \\
\hline Rheumatic & $17(24)$ & $5(16)$ & 0.324 & $39(85)$ & $18(95)$ & 0.267 \\
\hline Congenital & $29(41)$ & $19(59)$ & 0.092 & $0(0)$ & $0(0)$ & 1.000 \\
\hline Degenerative & $10(14)$ & $2(6)$ & 0.242 & $0(0)$ & $0(0)$ & 1.000 \\
\hline Senile calcification & $11(16)$ & $6(19)$ & 0.703 & $0(0)$ & $0(0)$ & 1.000 \\
\hline \multicolumn{7}{|l|}{ Valve lesion } \\
\hline Stenosis or mixed lesion & $64(91)$ & $29(91)$ & 0.894 & $33(72)$ & $17(90)$ & 0.123 \\
\hline Pure regurgitation & $6(9)$ & $3(9)$ & 0.894 & $13(28)$ & 2 (10) & 0.123 \\
\hline
\end{tabular}

Values are $\mathrm{n}(\%)$ unless stated otherwise.

AVR, aortic valve replacement; CABG, coronary artery bypass graft; CAD, coronary artery disease; DVR, AVR, aortic valve replacement; $\mathrm{CABG}$, coronary artery bypass graft;
double valve replacement; MVR, mitral valve replacement; NYHA, New York Heart Association.

New York Heart Association (NYHA) functional class) were documented. Data were obtained for all patients by interview and examination and by reviewing all medical records.

\section{Operative data}

The surgeon documented intraoperative findings and technical details of the procedure on a standard form immediately after each operation.

\section{Follow up data}

Patients were seen in the outpatients clinic at our institution six weeks after the operation and then between six months and one year later. At each follow up visit, thromboembolic events, bleeding events, NYHA functional class, heart rhythm, anticoagulant control, hospital admissions, and any other adverse events were documented. Beyond one year, patients were followed up by annual telephone interviews using a questionnaire. Patients who were unwilling to give information over the telephone were sent the questionnaire by post.

\section{Serum silver concentrations}

Serum concentration of silver was measured one week after operation in all patients with events, and in 14 patients in the Silzone group without events, matched for sex and valve position, as well as in 27 matched patients in the standard group. Results are reported as parts per million (ppm) based on a spectroscopic assay ${ }^{4}$ (Variant Spectra AA600 with GTA-100 graphite tube atomiser).

\section{Anticoagulant control}

All patients were anticoagulated with warfarin, with target international normalised ratios (INR) of 2.5 for aortic valve replacements in sinus rhythm and 3.0 for mitral and double valve replacements and for aortic valve replacement in atrial fibrillation. Actual INR values achieved were recorded for all patients. The proportions of INR measurements below, within, and above the therapeutic range of 2-3.5 were calculated and compared for the standard and Silzone groups.

\section{Definition of events}

Internationally accepted guidelines for reporting morbidity and mortality after valve replacement were used. ${ }^{5}$ Patients who developed clinical signs of stroke had the diagnosis confirmed and the type of stroke (ischaemic or haemorrhagic) defined by computed axial tomography or magnetic resonance imaging of the brain. Patients with the clinical picture of peripheral embolism had the diagnosis confirmed by Doppler scanning of the affected artery and by arteriography. The choice of imaging tests was left to the discretion of the physicians looking after each patient.

Transient ischaemic attacks (TIAs) were defined using criteria validated previously in a population based study of stroke. ${ }^{6}$ Prosthetic valve endocarditis was diagnosed using the Duke criteria. ${ }^{7}$ The causes of death were ascertained from medical records, necropsy reports, and death certificates obtained from the Office of National Statistics.

\section{Statistical analysis}

We used SPSS for Windows (version 10.0.7) and the SPLUS software package, version 2000 (Insightful Inc, Seattle, Washington, USA) for statistical analysis.

Continuous variables are described as mean (SD) and compared using the unpaired parametric $t$ test. Categorical variables are described by proportions and compared using the $\chi^{2}$ test or Fisher's exact test as appropriate. Patient survival curves were constructed using the actuarial method of Kaplan-Meier, ${ }^{89}$ and the significance of difference between 
Table 2 Kaplan-Meier event-free estimates: aortic valve replacement

\begin{tabular}{|c|c|c|c|c|c|c|c|c|c|}
\hline & \multicolumn{3}{|c|}{ Standard valve event-free (\%) } & \multicolumn{3}{|c|}{ Silzone valve event-free (\%) } & \multicolumn{3}{|c|}{ Standard - Silzone (\% and 95\% Cl) } \\
\hline & $3 \mathrm{~m}$ & $1 y$ & $3 y$ & $3 \mathrm{~m}$ & $1 y$ & $3 y$ & $3 \mathrm{~m}$ & $1 y$ & $3 y$ \\
\hline All thromboembolism & 97 & 93 & 85 & 94 & 91 & 88 & $3(-6$ to 12$)$ & $2(-10$ to 14$)$ & $-3(-19$ to 13$)$ \\
\hline Major thromboembolism & 100 & 100 & 97 & 97 & 97 & 97 & $3(-3$ to 9$)$ & $3(-3$ to 9$)$ & $0(-8$ to 8$)$ \\
\hline Major bleed & 100 & 100 & 92 & 100 & 91 & 84 & $0(0$ to 0$)$ & $9(-1$ to 19$)$ & $8(-8$ to 24$)$ \\
\hline Endocarditis* & 99 & 99 & 99 & 100 & 100 & 100 & $-1(-3$ to 1$)$ & $-1(-3$ to 1$)$ & $-1(-3$ to 1$)$ \\
\hline Reoperation & 100 & 100 & 98 & 100 & 100 & 100 & $0(0$ to 0$)$ & $0(0$ to 0$)$ & $-2(-5$ to 1$)$ \\
\hline Death & 99 & 97 & 94 & 100 & 100 & 91 & $-1(-3$ to 1$)$ & $-3(-7$ to 1$)$ & $3(-9$ to 15$)$ \\
\hline
\end{tabular}

*There was one case of probable endocarditis in the standard group, as assessed by the Duke criteria.

$\mathrm{Cl}$, confidence interval; $\mathrm{m}$, months; $y$, years.

Table 3 Kaplan-Meier event-free estimates: mitral or double valve replacement

\begin{tabular}{|c|c|c|c|c|c|c|c|c|c|}
\hline & \multicolumn{3}{|c|}{ Standard valve event-free (\%) } & \multicolumn{3}{|c|}{ Silzone valve event-free (\%) } & \multicolumn{3}{|c|}{ Standard - Silzone (\% and 95\% Cl) } \\
\hline & $3 \mathrm{~m}$ & $1 y$ & $3 y$ & $3 \mathrm{~m}$ & $1 y$ & $3 y$ & $3 \mathrm{~m}$ & $1 y$ & $3 y$ \\
\hline All thromboembolism & 93 & 88 & 80 & 65 & 65 & 65 & $28(0$ to 56$)$ & $23(-8$ to 54$)$ & $15(-18$ to 48$)$ \\
\hline Major thromboembolism & 100 & 100 & 95 & 65 & 65 & 65 & $35(8 \text { to } 62)^{*}$ & $35(5 \text { to } 65)^{*}$ & $30(0$ to 60$)$ \\
\hline Major bleed & 100 & 100 & 92 & 100 & 100 & 93 & $0(0$ to 0$)$ & $0(0$ to 0$)$ & $-1(-17$ to 15$)$ \\
\hline Endocarditis $†$ & 100 & 100 & 100 & 94 & 88 & 88 & $6(-5$ to 17$)$ & $12(-4$ to 28$)$ & $12(-4$ to 28$)$ \\
\hline Reoperation & 100 & 100 & 100 & 94 & 88 & 88 & $6(-5$ to 17$)$ & $12(-4$ to 28$)$ & $12(-4$ to 28$)$ \\
\hline Death & 91 & 91 & 87 & 89 & 79 & 74 & $2(-15$ to 19$)$ & $12(-10$ to 34$)$ & $13(-12$ to 38$)$ \\
\hline
\end{tabular}

*Significant difference between the groups.

†There was one definite and one probable case of endocarditis in the Silzone group, as assessed by the Duke criteria.

$\mathrm{Cl}$, confidence interval; $\mathrm{m}$, months; $y$, year.

the groups was tested by means of the log rank method. Ninety five per cent confidence intervals (CI) are given for the difference in freedom from events between the two groups at three months, one year, and three years, as expressed by the difference in event-free proportions.

\section{RESULTS}

\section{Baseline characteristics of the patients}

One hundred and sixteen patients received the standard valve and 51 received the Silzone valve. For patients with aortic valve replacement (70 standard and 32 Silzone) the groups were well matched for stroke risk factors such as diabetes, atrial fibrillation, arterial hypertension, coronary artery bypass grafting during the operation, current smoking, and previous cerebrovascular accident. For patients with mitral valve replacement (35 standard and 13 Silzone) or double valve replacement (11 standard and six Silzone), the patients receiving Silzone valves were younger and more likely to be female than those receiving standard valves. Patients with Silzone mitral valve replacements had more arterial hypertension but fewer coronary artery bypass grafts and less coronary artery disease than patients with standard mitral valve replacements (table 1). The mean (SD) NYHA class was $2.6(0.8)$ in the standard group and $2.8(0.7)$ in the Silzone group $(\mathrm{p}=0.19)$.

\section{Completeness and duration of follow up}

Follow up information was available in $97.4 \%$ of patients in the standard group and in all patients in the Silzone group. The mean duration of follow up was 4.7 (1.4) years in the standard group (maximum 6.2 years) and $3.0(0.9)$ years in the Silzone group (maximum 3.8 years). In all, 682 patient-years were available for analysis (153 Silzone and 529 standard).

\section{Thromboembolic events}

Major thromboembolism

In the standard group there was one peripheral embolism in a patient with a mitral prosthesis, and there were five embolic strokes (three in patients with aortic prostheses, one in a patient with a mitral prosthesis, and one in a patient with double prostheses).

In the Silzone group, all major thromboembolic events but one occurred in patients with mitral valve replacements (five cases) or double valve replacements (one case). In two patients with mitral prostheses, transoesophageal echocardiography done within days of the thromboembolic event showed thrombus on the sewing ring. This was subsequently confirmed at reoperation in one patient. The operative findings were unusual in that the large amount of thrombus on the sewing ring had no firm attachment to it two months after operation, and could simply be wiped off. The second patient had resolution of the thrombus after treatment with lepirudin.

Freedom from major thromboembolism and the percentage difference between the groups (standard minus Silzone) at three months, one year, and three years are given for aortic valve replacement (table 2) and mitral valve replacement/ double valve replacement (table 3 ). A positive difference between the groups favours the standard valve and a negative difference favours the Silzone valve. Significance is achieved only where the $95 \%$ confidence intervals for the difference exclude zero. Clinical details of the major thromboembolic events are summarised in table 4.

At three months, freedom from major thromboembolism after aortic valve replacement was 100\% in the standard group and $97 \%$ in the Silzone group (difference 3\%, 95\% CI, $-3 \%$ to $9 \%)$; after mitral valve replacement the corresponding figures were $100 \%$ and $65 \%$, respectively (difference 35\%, 95\% CI $8 \%$ to $62 \%$ ). All major thromboembolic events in the Silzone group occurred within three months after the operation. The Kaplan-Meier event-free curves were divergent for major thromboembolism, both for the groups as a whole $(\mathrm{p}=0.01)$ and for patients with mitral or double valve replacements $(\mathrm{p}<0.001)$ (fig 1$)$. 
Table 4 Standard versus Silzone: summary of major thromboembolic events

\begin{tabular}{|c|c|c|c|c|c|}
\hline INR & Age, sex & Valve type, position, size & $\begin{array}{l}\text { Days after } \\
\text { operation }\end{array}$ & Description of event/confirmatory tests & Comments \\
\hline $1.3-1.5$ & $70, M$ & SZ AVR, 21 & 4 & $\begin{array}{l}\text { Amnesia, hemianopia; parieto-occipital } \\
\text { ischaemic stroke/brain CT }\end{array}$ & $\begin{array}{l}\text { Heparin infusions; minimal } \\
\text { improvement }\end{array}$ \\
\hline $2.3-3.0$ & $62, F$ & SZ AVR 19 + SZ MVR, 27 & 22 & $\begin{array}{l}\text { Right sided hemiparesis (ischaemic } \\
\text { stroke)/brain CT }\end{array}$ & $\begin{array}{l}\text { Heparin infusions; some } \\
\text { improvement }\end{array}$ \\
\hline $2.6-3.8$ & $53, \mathrm{~F}$ & SZ MVR, 29 & 44 & $\begin{array}{l}\text { Ataxia; cerebellar ischaemic stroke/brain } \mathrm{CT} \text {; } \\
\text { thrombus on MVR at TOE }\end{array}$ & $\begin{array}{l}\text { Reoperated on } 03 / 08 / 98 \\
\text { asymptomatic since }\end{array}$ \\
\hline $1.9-2.2$ & $70, F$ & SZ MVR, 27 & 58 & $\begin{array}{l}\text { Right sided hemiparesis (ischaemic } \\
\text { stroke)/brain CT and MRI; thrombus on MVR } \\
\text { at TOE }\end{array}$ & $\begin{array}{l}\text { Lepirudin; resolution of thrombus, } \\
\text { marked improvement }\end{array}$ \\
\hline $2.8-3.2$ & $48, F$ & SZ MVR, 29 & 70 & $\begin{array}{l}\text { Right sided hemiplegia and dysphasia } \\
\text { (ischaemic stroke)/brain CT }\end{array}$ & Heparin; some improvement \\
\hline $3.0-3.8$ & $48, F$ & SZ MVR, 29 & 77 & $\begin{array}{l}\text { Right sided hemiplegia (ischaemic } \\
\text { stroke)/brain CT }\end{array}$ & Heparin; some improvement \\
\hline $3.1-3.8$ & $44, F$ & SZ MVR, 29 & 80 & $\begin{array}{l}\text { Embolism to the right femoral artery/Doppler } \\
\text { of femoral artery }\end{array}$ & Heparin; marked improvement \\
\hline $2.5-3.0$ & $47, \mathrm{~F}$ & ST MVR, 29 & 497 & $\begin{array}{l}\text { Acute worsening of pre-existing intermittent } \\
\text { claudication/arteriography, surgical } \\
\text { exploration. }\end{array}$ & $\begin{array}{l}\text { Congenital vascular abnormality } \\
\text { of femoral artery }\end{array}$ \\
\hline $1.3-1.1$ & $76, M$ & ST AVR, 21 & 581 & $\begin{array}{l}\text { Massive fatal stroke after warfarin discontinued } \\
\text { because of bleeding post-prostate surgery }\end{array}$ & \\
\hline $2.2-2.6$ & $64, M$ & ST AVR 29 + ST MVR 29 & 858 & $\begin{array}{l}\text { Acute embolic stroke: weakness of the left leg, } \\
\text { incompletely resolved after one month }\end{array}$ & \\
\hline 2.2 & $71, F$ & ST AVR & 889 & $\begin{array}{l}\text { Right sided hemiplegia (ischaemic stroke) } \\
\text { proceeded with } 2 \text { transient ischaemic attacks }\end{array}$ & Reoperated on $15 / 02 / 98$ \\
\hline \multirow[t]{2}{*}{$1.0-5.4$} & $71, F$ & ST AVR & 1669 & Ischaemic stroke & \\
\hline & $65, F$ & ST MVR 25 & 1972 & $\begin{array}{l}\text { Right sided hemiplegia and dysphasia } \\
\text { (ischaemic stroke) }\end{array}$ & \\
\hline
\end{tabular}

AVR, aortic valve replacement; F, female; INR, international normalised ratio (range of INR before the event); $M$, male; MVR, mitral valve replacement; ST, St Jude standard valve; SZ, St Jude Silzone valve;TOE, transoesophageal echocardiogram.

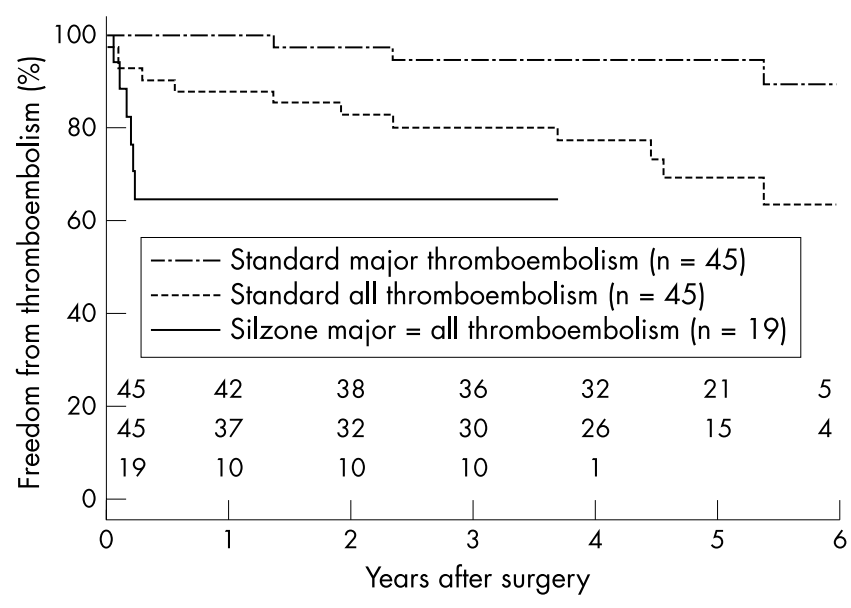

Figure 1 Kaplan-Meier curves of event-free periods for major thromboembolism and all thromboembolism in the standard group versus the Silzone group, for the mitral and double positions $(p<0.001$, log rank test). The single curve for the Silzone group represents both major thromboembolism and all thromboembolism.

\section{Minor thromboembolic events}

There were 30 TIAs in the standard group and six in the Silzone group. The event-free rates were not different between the two valve types. In one patient with recurrent TIA after mitral valve replacement with a Silzone valve, transoesophageal echocardiography detected thrombus on the sewing ring, which resolved after treatment with lepirudin.

\section{Other end points}

In the standard group, there was one reoperation for paravalvar leak, one case of probable endocarditis (as assessed by the Duke criteria), 11 major bleeding events, and 21 deaths from all causes. In the Silzone group, there were two reoperations (one following an ischaemic stroke and a second for endocarditis with paravalvar leak present on reoperation), two cases of endocarditis (one definite and one probable), six major bleeding events, and eight deaths from all causes. Event-free rates for major bleeding events, prosthetic valve endocarditis, reoperation, paravalvar leak, and death are given in tables 2 and 3.

\section{Serum silver concentrations}

Patients in the Silzone group had higher concentrations of silver in their serum than patients with standard valves $(0.01039$ $(0.00723) \vee 0.00015$ (SD 0.00011) ppm, respectively, $\mathrm{p}<0.0001)$. There was no difference in serum concentrations of silver in Silzone patients with events compared with those without events $(0.01016(0.00794) v 0.01082$ (0.00611) ppm, respectively, NS).

\section{Anticoagulant control}

The mean INR in the weeks before a major embolic event is given in table 4. Similar proportions of INR measurements were within the therapeutic range in the standard and Silzone groups (table 5).

\section{DISCUSSION}

We found unexpectedly that the St Jude Silzone valve in the mitral position was associated with an increased rate of

Table 5 Standard versus Silzone: anticoagulant control

\begin{tabular}{|c|c|c|c|c|c|c|}
\hline & \multicolumn{2}{|c|}{ INR $<2$} & \multicolumn{2}{|c|}{ INR 2-3.5 } & \multicolumn{2}{|c|}{ INR $>3.5$} \\
\hline & $n$ & $\%$ & $\mathrm{n}$ & $\%$ & $n$ & $\%$ \\
\hline Standard & 460 & 15 & 2213 & 70 & 477 & 15 \\
\hline Silzone & 176 & 16 & 814 & 72 & 145 & 13 \\
\hline
\end{tabular}


embolism early after surgery. The event rate of major thromboembolism was an order of magnitude higher than the published values for the St Jude standard valve, ${ }^{2}$ and also higher than the rate observed in patients who received the St Jude standard valve in our study.

The increased major thromboembolic risk seems to be an early phenomenon (less than three months after placement) and so patients who have now had a Silzone valve implanted for several years may not be at higher risk. There were trends for higher event rates for reoperation, death, and endocarditis in the Silzone group but these did not reach significance. There were no differences in the event rates for paravalvar leak, transient ischaemic attacks, or bleeding between the two groups. The only patient requiring reoperation for endocarditis had a Silzone valve, and it is possible that endocarditis in this patient was secondary to the excessive deposition of thrombus on the sewing ring that was observed at surgery.

The St Jude Silzone valve was withdrawn from the market in January 2000 because a multicentre prospective randomised trial of this prosthesis and the St Jude standard valve (the AVERT trial ${ }^{10}$ ) showed a significantly higher incidence of paravalvar leak among the Silzone valve patients. Although this trial also showed a higher incidence of stroke, reversible ischaemic neurological deficits, and valve thrombosis in patients with Silzone mitral valve replacement and double valve replacement, these differences failed to reach significance. By the time the Silzone valve was withdrawn, approximately 36000 prostheses had been implanted worldwide. It is therefore important to document their thromboembolic risk.

Although our study was not randomised, the patients with aortic valve replacement in the standard and Silzone groups were well matched for the prevalence of stroke risk factors, and patients with mitral valve replacement in the Silzone group had fewer risk factors. The groups also had similar anticoagulant control. If anything, the lower age and prevalence of coronary artery disease in the Silzone group should have favoured that prosthesis. As the prosthesis is otherwise identical to the St Jude standard valve, it is possible that the silver coating of the Silzone valve is more thrombogenic and that this may account for an increased incidence of thromboembolic events with this valve. The lack of normal attachment of thrombus to the sewing ring, as seen at operation, would increase the risk of embolism.

\section{Antibacterial action of silver}

Because of their antibacterial properties, silver and its compounds have been used for centuries for the topical treatment and prevention of infections. This effect involves inhibition of bacterial DNA synthesis by silver ions. ${ }^{11}$ Clinically, silver nitrate and silver sulfadiazine ${ }^{12}$ and nylon cloth impregnated with metallic silver ${ }^{13}$ are effective in preventing infection in burn wounds. Silver coating of indwelling urinary catheters may decrease the incidence of bacteriuria. ${ }^{14}$ In vitro and in animals, silver coated sutures have a bacteriostatic effect against a wide range of bacteria. ${ }^{15}{ }^{16}$ In dogs, cultures of abdominal aortic vascular prostheses impregnated with silver and inoculated with Staphylococcus aureus had significantly smaller colonies than those from prostheses without silver. ${ }^{17}$

The Silzone coating is "a dense layer of metallic silver which is deposited on the surface of individual fibrils of the valve sewing cuff, and is designed to inhibit attachment and colonisation of microorganisms to the cuff". ${ }^{18}$ In vitro and in vivo data on the bacteriostatic efficiency of this sewing cuff are conflicting. St Jude Medical reported that silver coating of sewing rings may provide additional antibacterial protection, ${ }^{19} 20$ but other investigators could not reproduce these results. ${ }^{21}$

An initial case report described "definitive cure of prosthetic endocarditis" with the Silzone valve, ${ }^{22}$ while a second report noted multiple recurrences of prosthetic endocarditis with this valve. ${ }^{23}$ A large randomised study (the AVERT trial) has recently reported no difference between Silzone and standard St Jude valves in the incidence of prosthetic valve endocarditis. ${ }^{10}$

\section{Cytotoxic and prothrombotic effects of silver}

A denuded, non-endothelialised artificial surface is a strong stimulus for platelet aggregation and ultimately for thrombosis, and so sewing rings of prosthetic valves are designed to promote their rapid incorporation into the anatomical annulus. The higher incidence of thromboembolic events in the early period after all valve replacements partly reflects the increased prothrombotic potential of the sewing ring which has not yet been covered by connective tissue and endothelium. An inhibitory effect by a silver coated sewing ring on fibroblasts may thus delay its normal incorporation into the annulus and predispose to thromboembolic events. Fibroblast inhibition could also prevent the normal attachment and stabilisation of thrombus on the sewing ring, predisposing to embolism. The predominance of thromboembolic events in the first three months after valve replacement in the patients with Silzone mitral valves is in keeping with this hypothesis, which is also supported by previous experimental observations.

Toxic effects are exerted through the release of silver ions into the tissues and their subsequent interaction with active moieties of membrane or enzyme proteins. ${ }^{24}$ Toxicity to fibroblasts may influence healing of the sewing ring. Silver produces a significant decrease in the proliferation of human fibroblasts in cell cultures, ${ }^{25}$ as well as cell damage. ${ }^{26}$ In mice, silver inhibits the incorporation of ${ }^{3} \mathrm{H}$-thymidine into DNA, and silver nitrate is more toxic than metallic silver owing to its greater rate of generation of ions. ${ }^{27}$ Silver impregnated collagen cuffs on tunnelled central venous pressure catheters have been shown to be toxic to fibroblasts in vitro and are associated with weak anchorage to subcutaneous tissues in comparison with Dacron cuffed catheters. ${ }^{28}$ It seems likely that the direct toxic effect of silver on tissues in general and fibroblasts in particular is also responsible for the increased rate of paravalvar leak associated with the Silzone valve reported by the AVERT trial. ${ }^{10}$ Confusion with "culture negative endocarditis" is possible, as at operation the appearances of silver induced annular necrosis resemble those of endocarditis. ${ }^{29}$ The possibility that the silver coated sewing ring may be carcinogenic has also been raised in a report describing a left atrial rhabdomyosarcoma arising adjacent to a Silzone mitral prosthesis one year after implantation. ${ }^{30}$

St Jude Medical reported good biocompatibility of silver coated polyethylene terephtalate fabric, with no cytotoxic effects until the concentration of silver in serum extract reached 1200 ppm. ${ }^{31}$ Valves with half coated and half uncoated sewing rings were implanted in the mitral position in juvenile sheep, then explanted and examined five weeks later. Fibrous tissue (pannus) was thinner on the coated cuffs than on the uncoated cuffs, a situation interpreted by the authors as showing "a more mature state of tissue reaction". However, thinner fibrous tissue covering may have been caused by inhibition of fibroblasts. None of the valves showed "excessive thrombosis". Extrapolating from these observations in sheep to estimate risks of thrombosis in man is methodologically insecure. For instance, platelet responses to artificial surfaces are highly dependent upon the species in which the surface is tested, and sheep platelets have been shown to attach much less and have lesser activation levels than human or porcine platelets. ${ }^{32}$ Furthermore, young animals show more vigorous healing than elderly human patients. Nonetheless, the serum silver concentrations observed in our study are highly unlikely to have caused any systemic cytotoxic effects.

Colloidal silver depletes cellular glutathione in erythrocytes, ${ }^{33}$ thus making them more susceptible to oxidative stress. Glutathione depletion of erythrocytes also occurs in 
diabetes mellitus, where it is associated with a conformational change of the membrane ("phospholipid flip-flop"), ${ }^{34}$ which may have a procoagulant effect. ${ }^{35}$

The only patient who needed reoperation for valve thrombosis in the Silzone group was diabetic, so the prothrombotic effects of silver on erythrocytes could have been enhanced by the diabetes.

Thus it is possible that the silver in the Silzone coating inhibits normal tissue ingrowth and endothelialisation of the prosthetic sewing ring and inhibits the normal organisation and stabilisation of thrombus on the sewing ring. This would then remain thrombogenic for longer than the standard ring and this effect could possibly be enhanced by the prothrombotic effects of silver on red blood cells.

\section{Surgical considerations}

In comparison with the findings in the AVERT study, ${ }^{10}$ the incidence of early major thromboembolism was slightly higher but the incidence of paravalvar leak leading to explantation was considerably lower. It is possible that issues relating to the surgical technique of implantation may have partly accounted for these differences. In this study, most mitral prostheses were implanted with continuous sutures with only three or four knots, whereas, although not stated, it is likely that the majority of mitral prostheses in the AVERT study ${ }^{10}$ were implanted with the more widely used technique of interrupted mattress sutures incorporating felt pledgets. Neither sutures nor pledgets were coated with Silzone. Extrapolating from the hypothesis that thrombus does not readily gain secure attachment to the silver impregnated surface of the Silzone sewing ring, the more sewing ring knots and pledgets there are, the greater the probability that the thrombus which normally accumulates on the sewing ring would find anchorage points to prevent embolism. In contrast, a surface with few very widely spaced knots and no pledgets may have been more likely to give rise to embolism.

This fundamental difference in suture technique may also account for the higher rate of explantation for paravalvar leak in the AVERT study. ${ }^{10}$ Interrupted mattress sutures with pledgets force the sewing ring into much firmer contact with the tissues of the annulus than continuous sutures, even inducing a degree of pressure necrosis if the sutures are overtightened. It is possible that this firmer initial fixation may have enhanced the toxic necrosis induced by the silver coated sewing ring, as seen in the pathology study of Butany and colleagues, ${ }^{29}$ leading to a higher incidence of paravalvar leak than in our study.

The appearances of silver induced annular necrosis and prosthetic endocarditis with detachment are very similar ${ }^{29}$ and it may be almost impossible to differentiate between them in the absence of identifiable organisms on blood culture or in the annular tissues. It is interesting that the AVERT study ${ }^{10}$ found a high incidence of endocarditis in both groups of patients (more than 3\% per year-that is, more than twice the objective performance criterion set for prosthetic heart valves by the FDA). Although it seems possible that difficulty in distinguishing between endocarditis and a toxic necrosis induced paravalvar leak could have accounted for a higher incidence in the Silzone group, the equally high incidence in the standard group is hard to explain. Whatever the explanation, this underlines the difficulty in ascribing events to one category only, when in reality event mechanisms may be difficult to differentiate or may exist in combination-for example, embolism, endocarditis, and paravalvar leak. In this study, there was only one case of culture proven prosthetic endocarditis with detachment among the Silzone patients, but the large amount of associated thrombus on the mitral prosthesis suggested that this may have been the primary event, with secondary infection occurring later. No cases of endocarditis occurred in patients with the standard valve.

\section{Limitations of the study}

This was a non-randomised study which used noncontemporaneous controls, and the numbers are relatively small. However, the "standard" and "Silzone" groups were well matched for the prevalence of baseline risk factors for stroke, and follow up was completed in a single centre.

The causes of death in patients who died outside hospital were obtained from the death certificates. It is possible that some of the deaths (for example, those caused by "congestive heart failure") might have been valve related, but without a necropsy examination this could not be confirmed.

\section{Conclusions}

In our experience, the Silzone valve in the mitral position is associated with an increased incidence of early major thromboembolic events, probably related to impaired adherence of thrombus to the silver coated sewing ring. Intensive follow up of patients who have received this valve is recommended, with a low "threshold" for undertaking transoesophageal echocardiography, particularly in patients with mitral prostheses.

\section{ACKNOWLEDGEMENTS}

The study was supported by the British Heart Foundation, the Heart Research Fund for Wales, and St Jude Medical Inc. We thank Stephen Noonan SRN for help with collecting the data and Stephen C Smith MLSO for measuring silver concentrations in plasma.

\section{Authors' affiliations}

A lonescu, E G Butchart, Department of Cardiothoracic Surgery, University Hospital of Wales, Cardiff, UK

A G Fraser, Department of Cardiology, University Hospital of Wales J Giddings, Department of Haematology, University Hospital of Wales N Payne, G L Grunkemeier, Medical Data Research Center,

Providence Health System, Portland Oregon USA

\section{REFERENCES}

1 Food and Drug Administration. Pre-market approval number P810002, supplement number 5046. Available from: URL: http://www.fda.gov/cdrh/pma/pmaapr98.html

2 Cannegieter SC, Rosendaal FR, Briet E. Thromboembolic and bleeding complications in patients with mechanical heart valve prostheses. Circulation 1994;89:635-41.

3 Butchart EG, Bodnar E. Thrombosis, embolism and bleeding. London: ICR Publishers, 1992

4 Wan AT, Conyers RA, Coombs CJ, et al. Determination of silver in blood, urine, and tissues of volunteers and burn patients. Clin Chem 1991;37:1683-7.

5 Edmunds LH, Clark RE, Cohn LH, et al. Guidelines for reporting morbidity and mortality after cardiac valvular operations. Ad hoc liaison committee for standardizing definitions of prosthetic heart valve morbidity of the American Association for Thoracic Surgery and the Society of Thoracic Surgeons. J Thorac Cardiovasc Surg 1996;1 12:708-11.

6 Bamford J, Sandercock P, Dennis M, et al. A prospective study of acute cerebrovascular disease in the community: the Oxfordshire community stroke project 1981-1986: methodology, demography and incident cases of first-ever stroke. J Neurol Neurosurg Psychiatry 1988;51:1373-80.

7 Durack DT, Lukes AS, Bright DK. New criteria for diagnosis of infective endocarditis: utilization of specific echocardiographic findings. Duke endocarditis service. Am J Med 1994;96:200-9.

8 Grunkemeier GL. Statistical analysis of prosthetic valve series. In: Rabago G, Cooley DA, eds. Heart valve replacement, current status and future trends. Mount Kisco, New York: Futura Publishing Co, 1987:1 1-26.

9 Kaplan EL, Meier P. Nonparametric estimation from incomplete observations. J Am Stat Assoc 1958;53:457-81.

10 Schaff HV, Carrel TP, Jamieson WRE, et al. Paravalvular leak and other events in Silzone-coated mechanical heart valves: a report from AVERT. Ann Thorac Surg 2002;73:785-92.

11 Hall RE, Bender G, Marquis RE. Inhibitory and cidal antimicrobial actions of electrically generated silver ions. J Oral Maxillofac Surg 1987;45:779-84.

12 Harrison HN. Pharmacology of sulfadiazine silver. Its attachment to burned human and rat skin and studies of gastrointestinal absorption and excretion. Arch Surg 1979;114:281-5.

13 Deitch EA, Marino AA, Malakanok V, et al. Silver nylon cloth: in vitro and in vivo evaluation of antimicrobial activity. J Trauma 1987;27:301-4. 
14 Akiyama H, Okamoto S. Prophylaxis of indwelling urethral catheter infection: clinical experience with a modified Foley catheter and drainage system. J Urol 1979;121:40-2.

15 Tsai WC, Chu CC, Chiu SS, et al. In vitro quantitative study of newly made antibacterial braided nylon sutures. Surg Gynecol Obstet 1987; 165:207-11

16 Chu CC, Tsai WC, Yao JY, et al. Newly made antibacterial braided nylon sutures. I. In vitro qualitative and in vivo preliminary biocompatibility study. J Biomed Mater Res 1987:21:1281-300.

17 Benvenisty Al, Tannenbaum G, Ahlborn TN, et al. Control of prosthetic bacterial infection: evaluation of an easily incorporated, tightly bound, silver antibiotic PTFE graft. J Surg Res 1988;44:1-7.

18 Schaff $\mathbf{H}$, Carrel T, Steckelberg JM et al. Artificial valve endocarditis reduction trial (AVERT): protocol of a multicenter randomized trial. J Heart Valve Dis 1999;8:131-9.

19 Tweden KS, Cameron JD, Razzouk AJ, et al. Silver modification of polyethylene terephthalate textiles for antimicrobial protection. ASAIO J 1997:43:M475-81.

20 Illingworth BL, Tweden K, Schroeder RF, et al. In vivo efficacy of silver-coated (Silzone) infection-resistant polyester fabric against a biofilm-producing bacteria, Staphylococcus epidermidis. J Heart Valve Dis 1998;7:524-30.

21 Darouiche RO, Meade R, Mansouri $M$, et al. In vivo efficacy of antimicrobial-coated fabric from prosthetic heart valve sewing rings. $J$ Heart Valve Dis 1998;7:639-46.

22 Carrel T, Nguyen T, Kipfer B, et al. Definitive cure of recurrent prosthetic endocarditis using silver-coated St Jude Medical heart valves: a preliminary case report. I Heart Valve Dis 1998:7:53 1-3.

23 Kjaergard HK, Tingleff J, Abildgaard U, et al. Recurrent endocarditis in silver-coated heart valve prosthesis. J Heart Valve Dis 1999;8:140-2.
24 Hollinger MA. Toxicological aspects of topical silver pharmaceuticals. Crit Rev Toxicol 1996;2:255-60.

25 McCauley RL, Linares HA, Pelligrini V, et al. In vitro toxicity of topical antimicrobial agents to human fibroblasts. J Surg Res 1989:46:267-74

26 Liedberg $\mathbf{H}$, Lundeberg T. Assessment of silver-coated urinary catheter toxicity by cell culture. Urol Res 1989;17:359-60.

27 Kuroyanagi Y, Kim E, Shioya N. Evaluation of a synthetic wound dressing capable of releasing silver sulfadiazine. J Burn Care Rehabil $1991 ; 12: 106-15$

28 Hemmerlein JB, Trerotola SO, Kraus MA, et al. In vitro cytotoxicity of silver-impregnated collagen cuffs designed to decrease infection in tunneled catheters. Radiology 1997;204:363-7.

29 Butany J, Scully HE, VanArsdell G, et al. Prosthetic heart valves with silver-coated sewing cuff fabric: early morphological features in two patients. Can J Cardiol 2002;18:733-8.

30 Grubitzsch H, Wollert HG, Eckel L. Sarcoma associated with silver coated mechanical heart valve prosthesis. Ann Thorac Surg 2001:72:1739-40.

31 Tweden KS, Cameron JD, Razzouk AJ, et al. Biocompatibility of silver-modified polyester for antimicrobial protection of prosthetic valves. $J$ Heart Valve Dis 1997;6:553-61.

32 Goodman SL. Sheep, pig, and human platelet-material interactions with model cardiovascular biomaterials. J Biomed Mater Res 1999:45:240-50.

33 Garner M, Reglinski J, Smith WE, et al. The interaction of colloidal metals with erythrocytes. J Inorg Biochem 1994;56:283-90.

34 Wilson MJ, Richter-Lowney K, Daleke DL. Hyperglycemia induces a loss of phospholipid asymmetry in human erythrocytes. Biochemistry 1993:32:1 1302-10

35 Kuypers FA. Red cell membrane damage. J Heart Valve Dis 1998;7:387-95.

\section{IMAGES IN CARDIOLOGY}

\section{Transoesophageal echocardiography imaging of a large left atrium thrombus: a two and a half year follow up}

$\mathrm{P}$

atients with left atrial thrombus are considered at high risk for thromboembolic events. Transoesophageal echocardiography (TOE) is highly accurate for diagnosis of atrial thrombi and gives the possibility to serially evaluate the effects of anticoagulant treatment.

We present the case of a 79 year old woman who was admitted to the hospital suffering from acute stroke. She had a history of coronary artery disease, chronic atrial fibrillation, and permanent pacemaker. She was not treated with anticoagulants. Clinical diagnosis was confirmed by brain computed tomography, which showed two infarcts in the right posterior cerebral artery perfusion area and a third haemorrhagic infarct in the left middle cerebral artery perfusion area. She underwent a TOE study, which showed a large thrombus, partly mobile, on the posterior atrial wall (dimensions: $2.71 \mathrm{~cm}$ length and $2.19 \mathrm{~cm}$ width; surface area $4.45 \mathrm{~cm}^{2}$ ) (middle panel: A, length; B, width; C, surface area; LA, left atrium; THRO, thrombus). The patient started anticoagulation treatment (acenocoumarol). The thrombus size remained unchanged in a second study seven days later, while a new TOE 20 days later showed a slight decrease of the thrombus dimensions $(2.44 \mathrm{~cm}$ length and $1.68 \mathrm{~cm}$ width, surface area

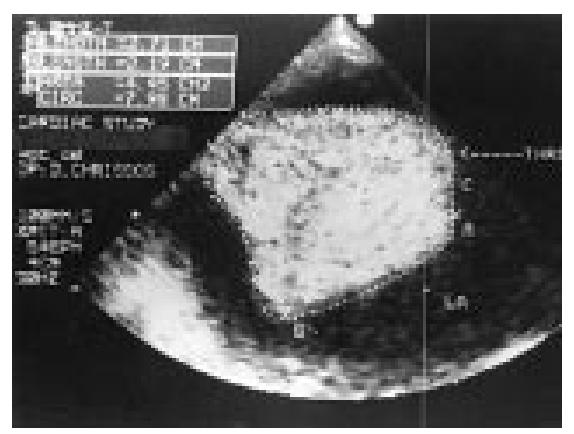

$3.31 \mathrm{~cm}^{2}$ ) (right upper panel: AO, aorta, RA, right atrium). The patient's condition improved steadily and she was discharged from hospital 20 days after the start of anticoagulation treatment. Forty days later the TOE showed complete resolution of atrial thrombus (right lower panel). The TOE study remained unchanged five months and two and a half years later, while the patient's condition further improved.

The striking clinical finding was that the thrombus resolution was not accompanied by any new neurological events, even though its size was significant.

\section{Chrissos}

\section{Loupa}

P Antonatos dimchrissos@hotmail.com
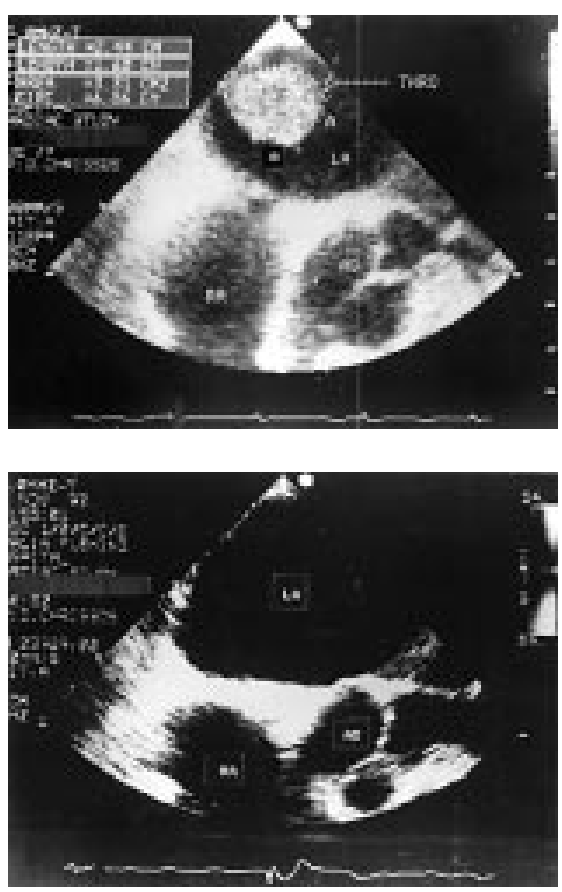